\section{Edgard Carone *}

\footnotetext{
R. Adm. Emp., Rio de Janeiro,

\title{
Coronelismo: Definição Histórica e Bibliografia
}

"O vocábulo coronelismo, introduzido desde muito em nossa língua com acepção particular. de que resultou ser registrado como brasileirismo nos léxicos aparecidos do lado de cá do Atlântico, deve incontestàvelmente a remota origem do seu sentido translato aos autênticos ou falsos coronéis da extinta Guarda Nacional. Com efeito, além dos que realmente ocupavam nela tal pôsto, o tratamento de coronel começou desde logo a ser dado pelos sertanejos a todo e qualquer chefe político, a todo e qualquer potentado;" ... "a Guarda Nacional nasceu a 18 de agôsto de 1831, tendo tido o Padre Diogo Antônio Feijó por pai espiritual... durante quase um século, em cada um dos nossos municípios existia um regimento da Guarda Nacional. 0 pôsto de coronel era geralmento concedido ao chefe político da comuna... Eram, de ordinário, os mais opulentos fazendeiros ou os comerciantes e industriais mais abastados, os que exerciam, em cada município, o comando - em chefe da Guarda Nacional." 1
A explicação de Basílio de Magalhães pretende sòmente definir o conceito de coronelismo, sem estudar a sua problemática e origens.

No entanto, a razão primeira do coronelismo é o fator geográfico, que vai estar intrìnsecamente ligado à formação das grandes propriedades. A formação complexa e individualista da nossa expansão territorial se faz através de núcleos isolados. Portuguêses nobres, comerciantes ricos e militares a serviço da Coroa, etc., recebem sesmarias, formando os primeiros núcleos independentes e iniciando, por razões várias, um processo que prossegue no Império e República. Enquanto os latifúndios se estendem, pràticamente não existe a ação do Estado; a ausência do poder público facilita a presença do poder

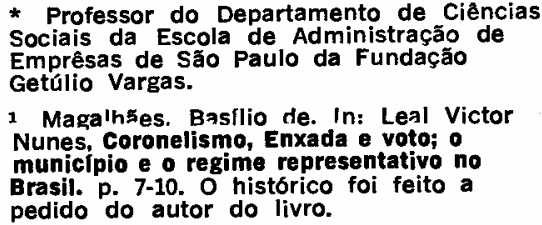
Emprêsas de Săo Paulo da Fundação Getúlio Vargas.

1 Magalhstes. Basflio de. In: Leal Victor Nunes, Coronelismo, Enxada e voto; O municipio e o regime representativo no Brasil. p. 7-10. O histórico foi feito a pedido do autor do livro. 
privado, que se arroga no direito de todos os atributos "legais".

A formação dispersa torna o problema do mandonismo um processo nacional.

Desde a Colónia os grandes proprietários de terra vêm dominando de fato, e tornando-se os homens bons (ricos), que compõem as câmaras municipais. Os barões e coronéis representam simples continuidade do sistema anterior, havendo, no entanto, maior amplitude de representação legal. É que a partir da Independência e, principalmente, do federalismo da Primeira República, acentuam-se os predomínios locais, uma vez que são os representantes das oligarquias latifundiárias que dominam o legislativo e executivo.

A partir do Império, o mandonismo local é denominado indistintamente de coronelismo (maior parte do Brasil), caudiIhismo (Rio Grande do Sul), chefismo (vale do São Francisco), etc. A regionalização de nomes mostra a expansão e unidade do problema, que se traduz também em fatôres extrínsecos comuns. Como diz um publicista uruguaio, "caudiIho quer dizer fôrça própria, autoridade própria e, portanto, autonomia." 2

As características exteriores nascem de uma situação objetiva inicial - a posse dos meios de produção, que é a terra. E o seu domínio liga-se à existência do clã familiar: o chefe, - patriarca, o coronel, é aquêle que domina a estrutura familiar e que lhe consegue transmitir "tranqüilidade, segurança, vigilância, e ritmo dos dias serenos numa população que parecia constituir a família comum, com parentes turbulentos, brigões, arrebatados, mas, ao final, acomodados, submissos, ajustados à doce seqüência da vida triste feliz." 3

A dependência familiar ajunta-se a dependência dos agregados: escravos, ex-escravos, trabalhadores de eito assalariados, todos necessitam do trabalho, alimentação e proteção do senhor. $\mathrm{E}$ a forma de autoridade é tão larga que se estende também para os domínios próximos do pequeno comércio e dos profissionais liberais que circulam na zona, pois, a pressão pessoal ou política permite o domínio sôbre todos.

Naturalmente, a ação sôbre os agregados é mais forte do que com os outros. Com os primeiros, existe troca de favores: "para êle (o coronel), favor é dar um dia de serviço quando o pobre está passando fome; é não deixar que vá prêso quando se embriaga e tenta subverter a ordem pública; é dar a roupa e o calçado para votar; é dar - remédio e o médico quando o pobre está doente; é afiançá-lo na loja do comerciante para comprar a roupa; é dar-lhe terra e fornecer dinheiro para plantar e limpar o roçado. Em troca dêsses favores exige, naturalmente, outros favores. Exige que leve e traga os recados. Exige que vá à feira comprar e trazer as mercadorias. Exige respeito e acatamento às suas ordens. Exige que açoite ou mate o adversário quando the ofende. Exige que bote água e lenha em casa. Exige, finalmente, 0 voto. 0 voto que é o instrumento poderoso com que o chefe mantém o seu prestígio, o seu domínio, a sua posição de Iíder. Sem isso estaria terminado 0 seu ciclo, a sua gestão, o seu feudo." 4

Sendo o poder do coronel local, é grande o seu contrôle sôbre empregos públicos; e, também, na nomeação ou demissão das autoridades; como no aumento ou baixa de impostos, segundo a sua conveniência ou inconveniência, quando quer servir amigos ou prejudicar outros. Os casos se repetem de uma maneira monótona e, um exemplo, ao acaso, é o acôrdo de paz entre os coronéis do interior da
Bahia e o representante do govêrno federal, em 1920: um Horácio de Matos ou Anfilófio Castelo Branco sublinham o direito que possuem sôbre a sua zona de influência, incluindo num dos itens do acôrdo que, "seja quem fôr o governador da Bahia, terá que entregar, sob o patrocínio do comando da região militar dêsse estado, a direção político-administrativa dos municípios de Remanso, Casa Nova e XiqueXique aos revolucionários, seus atuais ocupantes e dirigentes..." 5

Domínio significa privilégio e poder único. Num regime onde as oportunidades de vida são limitadas e a liberdade de trabalho restrita, torna-se fácil, ao coronel, obter um contrôle rígido sôbre tôdas as opções locais. Daí, todos quererem ser situacionistas, isto é, partidários do poder local e beneficiários da situação. No entanto, a oposição existe, quando não pode ser situação ou subsistem motivos de desavenças pessoais e familiares.

Situação e oposição são posições que se refletem em nuanças diferentes em cada um dos estados: as divergências vão do assassinato ao ostracismo pessoal, ou político. O coronel João Duque, chefe de Carinhanha (vale do São Francisco, Bahia), dizia sorrindo, quando alguém lhe perguntava se mandava matar os adversários: "meu filho, em política não há assassinatos: há remoção de obstáculos". ${ }^{6}$ Por sua vez, um Horácio de Matos revida, atacando os seus desafetos, com um exército coronelístico; e Totó Paes cerca

\footnotetext{
2 Felde, Alerto Zum.In: Moraes, Carlos Dantes de Figuras e cicios da historia riograndense. $\mathrm{p}$. 135-6.

- Cascudo, Luís da Câmara. História da República no Rio Grande do Norte. p. 39-40.

- Melo, M. Rodrigues de. Patriarcas e carreiros. p. 135-6.

- In Carone, Edgard. A Primeira República, texto e contexto. $O$ incidente faz parte da Revolta de 1920, na Bahia. O grifo é nosso

- Lins, Wilson. 0 médio săo Francisco. p. 111.
} 
e ataca Cuiabá; e um Fernando Prestes I-vanta suas tropas para atacar os revolucionários tenentistas que ocupam a cidade $d$ - São Paulo; e Pinheiro Machado combate os federalista, com tropas levantadas por êle. Senão, é Horácio de Matos que consegue o beneplácito do govêrno federal para que fô:se retirado de Campestre "o coronel Fabrício e seus amigos, com a proibição de ali voltarem". ${ }^{7}$

No entanto, poder local também é tradução de beneplácito e favores conseguidos junto à política dominante do estado. É verdade que 0 federalismo republicano dá ao estado, e êste, por sua vez, ao município, uma série de regalias políticas e financeiras. $A$ interdependência entre ambos é fundamental. Mas, os favores que recebe do estado, os empregos públicos estaduais que distribui, as verbas extras que consegue e a neutralização ou beneplácito das autoridades policiais são os benefícios de uma política comum entre o coronel e a autoridade maior. 0 elo de ligação entre ambos é o voto.

A subordinação quase total ao coronel significa, pragmàticamente, apoio a tôdas as suas vontades. $E$ o voto é uma das expressões dêste acatamento. Numa visita eleitoral ao interior do Rio Grande do Norte, Ferreira Chaves, candidato ao govêrno estadual, ouviu do coronel José Bezerra, o seguinte: "vim aqui a chamado do meu irmão Silvino Bezerra, que é meu irmão mais velho, e que o considero como meu chefe político... Amanhã, - senhor passará em Currais Novos, município de que sou representante; ali não haverá foguete, banquete, falação e é provável que não lhe apareça ninguém com intuito de manifestação; vai o senhor se hospedar na casa de meu sobrinho Sérvulo Pires, porque o senhor anda aqui atrás de voto e não de manifestações políticas; tenho no meu município o que outro, no estado, provàvelmente não tenha: 800 eleitores que tenho em Currais Novos são seus de porteira batida e mais nos municípios vizinhos que ouvirem minha orientação política." 8

O domínio familiar e público é, assim, a característica do fenômeno do coronelismo. E êle persiste e se transforma à medida que o poder do estado aumenta e entra em conflito com algumas destas prerrogativas particularistas. A limitação progressiva da autonomia municipal, a nomeação de delegados de carreira, o aumento populacional das cidades e, depois de 1930, as formas centralizadas de govêrno, etc., fazem com que as formas clássicas de domínio se diluam cada vez mais, metamorfoseando-se em novas atitudes. O que se dá é mudança, não extinção de um fenômeno.

\section{Como síntese do momento} máximo do coronelismo, reproduzimos as palavras de $M$. Rodrigues de Melo, que retrata com grande precisão e romantismo o tipo clássico dêste coronel que desapareceu e marcou grande parte da vida social e política brasileira: "recordo-me de como ouvi, pela primeira vez, na minha meninice, falar dêsse grande seridoense (Seridó, Rio Grande do Norte). O seu nome soava como uma nota de clarim, vibrando nas quebradas das serras e dos vales, como defensor da honra alheia, dos limites da propriedade privada, da môça ofendida, do pobre que apelava para a sua proteção, inimigo da prepotência, defensor dos hábitos e costumes do seu povo, transformados por uma sedimentação de vários séculos em norma de vida ou código de lei. No seu município predominou por muito tempo o regime do Estado sou eu. 0 município era êle. $A$ lei era êle. $O$ juiz, o delegado, o padre, era êle. Tudo isso, é lógico, dentro do decôro, da prudência, da polidez, da cordura que o seu nome de homem superior, inteligente, experimentado, abrangia, sem dizer que estava mandando. A sua sombra, reflexo superabundante de sua personalidade de escol, ampliava-se por por tôda a vasta região do Seridó. Basta dizer que durante a sua vida, nunca o município de Currais Novos foi policiado por fôrça do govêrno. Os seus homens-de-confiança eram os guardiōes de segurança da cidade, do município, da redondeza. Vem daí, em grande parte, - seu prestígio, a sua fôrça moral, perante o povo bom, honesto, e simples do sertão. Antes de sua morte, Currais Novos era uma espécie de paraíso. As famílias viviam unidas confraternizadas na dor, no sofrimento, na alegria, em tôrno do seu chefe." 9

0 que vem a seguir é uma pequena bibliografia crítica sôbre o coronelismo. ${ }^{10}$ Poucos livros foram escritos, até agora, sốbre o problema específico do coronelismo, ${ }^{11}$ a maior parte dêles abordando o tema de maneira esporádica. Um dos únicos que trata diretamente do assunto, o de Victor Nunes Leal, é, infelizmente, mais um estudo jurídico do que histórico-sociológico. E na literatura menor, muitas vêzes elogiosa, que vamos encontrar dados mais ricos e vívidos. 0 melhor exemplo é o trabalho de Américo Chagas sôbre Horácio de Matos: apesar de seus senões é uma fonte inestimável de dados. 0 . exemplo se repete na maior parte desta literatura menor, que se encontra editada por todo o Brasil, mas que é grandemente inacessivel.

\footnotetext{
7 Carone, Edgard. ibidem. p. 85. Ver estes casos in: Carone, Edgard A República velha, instituiģoes e classes sociais. cap. sôbre coronelismo.

8 Melo, M. Rodrigues de. Ibidem. p. 94.

- Melo, M. Rodrigues de. Ibidem. p. 52-3.

10 A bibliografia foi feita sob orientação de Melania Della Tôrre.

11 A nossa ênfase 6 sôbre o problema na Primeira República. Os estudos que tratam de fatos anteriores e posteriores a esta época aparecem por estarem ligados ao momento estudado.
} 
Finalmente, queremos chamar a atenção para o critério adotado em relação à bibliografia: em vez de fazer uma crítica de valor, preferimos divulgar o seu conteúdo; a nossa opinião aparece como um fator secundário e ocasional. o que é fundamental é a matéria bruta em contribuição a futuros aprofundamentos do problema.

ALBUQUERQUE, Ulysses Lins de. Um sertanejo e o sertão. Rio de Janeiro, José Olympio, 1957. $387 \mathrm{p}$.

Relata a vida, os costumes e a economia do sertão pernambucano.

Dados e episódios sôbre as formas políticas dominantes; 0 cangaceirismo a serviço dos coronéis; as formas eleitorais vigentes até 1930 . Primitivas indústrias do sertão (existentes até o fim do século $X I X)$ : iluminação, instrumentos domésticos, saúde e alimentação. $O$ autor é originário de Alagoa de Baixo.

ALMEIDA, Elpídio de. História de Campina Grande. Campina Grande, Paraíba, Livraria Pedrosa, 1962. 424 p.

Monografia histórica, política e cultural do maior município da Paraíba. Exemplos de rivalidades políticas locais e soluções através de lutas armadas. Domínio de Álvaro Machado.

ALMEIDA, Horácio de. Brejo de Areia. Rio de Janeiro, Ministério da Educação, 1958. 303 p. il.

Monografia sôbre o município de Brejo de Areia, estado da Paraíba. Estudo histórico, político e cultural do segundo município do Estado e do seu fastígio e decadência.

Apesar do trabalho ser regional, o autor busca os fatos exteriores como explicação. Dêsse modo, os dados sôbre o comêço da República na Paraíba são elucidativos. 0 domínio oligárquico de Alvaro Machado é bem descrito. Os exemplos de lutas políticas locais ou estaduais (onde eram utilizadas fôrças do exército ou cangaceiros) são abundantes.

ANSELMO, Otacílio. Padre Cícero, mito e realidade. Rio de Janeiro, Civilização Brasileira, 1968. 584 p. il.

Tentativa de desmistificação da vida e atos do Padre Cícero. Contém documentação inédita e importante, porém, a análise descamba para um partidarismo negativista.

Padre Cícero e Floro Bartolomeu. Zona do Cariri. Coronelismo no Cariri. Chegada de Floro ao Cariri (1908). Sua vida. Vida do Padre Cícero. Coronelismo e prestígio político. Coronelismo na Paraíba. Oligarquia Acioli. Vida de Nogueira Acioli. Oposição a Nogueira Acioli. Sucessão de Nogueira Acioli em 1911. Govêrno Franco Rabelo; medidas que tomou no govêrno: não apóia candidatura de Pinheiro Machado ao govêrno federal; preparo da revolução cearense de 1913-1914. Antecedentes da revolução. Atitude de dubiedade de Franco Rabelo. Preparo da defesa de Joàzeiro. Revolução militar (dezembro de 1913 a março de 1914); ajuda do govêrno federal aos revoltosos; derrota das tropas legalistas; apoio do povo de Fortaleza a Franco Rabelo; estado de sítio no Ceará (março 1914); queda de Franco Rabelo e subida do comandante da região, General Setembrino de Carvalho. Novas eleições (maio 1914). Lampeão em Joàzeiro. Legião Cearense do Trabalho (integralismo).

ASSUNÇAO, Herculano Teixeira D'. A campanha do Contestado. As operaçōes da coluna do Sul: operações de guerra, natureza do seu teatro e seus ensinamentos. Retrospecto das expedições anteriores. Síntese das operações das colunas do Norte, Leste e Oeste. Costumes e hábitos sertanejos.

Fanatismo e banditismo. Fatos e episódios. Recursos militares das zonas colonial e serrana. Belo Horizonte, Oficial, 1917-1918. 2 v. il.

Apesar de ter participado da Coluna Sul, o autor historia a ação das quatro colunas que participaram da Campanha do Contestado. O livro é medíocre e cheio de observações erradas sôbre os problemas sociais, políticos e econômicos da região.

Dados sôbre as quatro colunas. Lutas de coronéis no Paraná e Santa Catarina. Area geográfica do conflito. Proclamação do General Setembrino antes do ataque a Santa Maria. Tomada do reduto de Tavares.

BARBOSA, Mário Ferreira. Dr. Góes Calmon: a sua vida e o seu govêrno na Bahia. Bahia. Banco Econômico da Bahia, 1933. $126 \mathrm{p}$.

De família rica e grande tradição política, Góes Calmon torna-se governador da Bahia (1924-1928), como candidato de conciliação.

Pequena biografia de Góes; suas atividades bancárias e jurídicas; relatório de sua ação como governador do estado; reação estudantil em Pernambuco à demissão de J. J. Seabra do cargo de professor na Faculdade de Direito (1892); luta contra a influência do coronelismo na Bahia.

BARRETO, Dantas. Expedição a Mato Grosso: a Revolução de 1906. Rio de Janeiro, Laemmert, 1907. 221 p.

0 autor, general do exército, foi o chefe da expedição mandada por Afonso Pena para socorrer o Governador Antônio Paes de Barros. Quando ela chega a Cuiabá, êste já fôra morto. 
O livro parte de premissas sociológicas primárias para compreender o fenômeno político matogrossense. Deixando de lado êste aspecto, pode-se ver, através de suas páginas, 0 pensamento oficial: Antônio Paes era despótico, mas aliado de Afonso Pena.

Hostilidade existente entre as fôrças do exército e do govêrno estadual. Ação de Serzedelo Corrêa na Coligaçãa Matogrossense. Relato de João Paes sôbre o ataque à Usina Conceição e o massacre da baía de Garcez (1901). Acôrdo do $1 .^{\circ}$ de maio de 1906 e seu rompimento. Revolução de 1906. Inexistência de fôrças federais para reprimir a revolução.

CABRAL, C. Castilho. Batalhões patrióticos na Revolução de 1924. São Paulo, Liberdade, 1927. 237 p. il.

Material precioso para o problema do coronelismo em São Paulo e achegas à revolução de 1924.

Concentração de tropas coronelísticas em Itapetininga (7-7-1924) e combates travados. Formação de duas grandes companhias de exploração agrária em Presidente Prudente (1917). Domínio de Ataliba Leonel na zona do Piraju. Ata da formação do Batalhão Ataliba Leonel. Número de voluntários. Os batalhões Fernando Prestes e Washington Luís. Tentativa de sublevação das tropas coronelísticas, em Sorocaba. Bauru e as tropas coronelísticas do deputado de Lorena de Vergueiro. Govêrno federal manda oficiais e armamentos para ajuda aos coronéis. Simpatias pela revolução (Sorocaba). As ofensivas coronelísticas de Sorocaba, Pantoko, São Roque, Assis, Presidente Prudente. Coronelismo e gastos com as despesas das tropas. Batalhão da Polícia de Santa Catarina. Revolucionários incendeiam armazéns da Cia. Marcondes, um dos sustentáculos das fôrças coronelísticas (Presidente Prudente). Classe média e simpatia pela revolução (Presidente Prudente). "Dinheiro" revolucionário. Passagem dos revolucionários para Mato Grosso. Dissolução dos batalhões patrióticos.

CALDAS, Joaquim Moreira. Porque Dantas assassinou João Pessoa. Rio de Janeiro, Mendes Júnior, s/e. 174 p. fot.

Defesa de João Dantas. 0 autor mostra a incongruência da Aliança Liberal e o despotismo do govêrno João Pessoa. Dados sôbre Princesa. João Pessoa e seu anti-revolucionarismo; seu govêrno e atitude atribulária contra os funcionários; a política tarifária e a luta contra - sertão; luta contra as grandes famílias do sertão; escolha da chapa federal e a cisão João Suassuna e José Pereira; sua política contra Suassuna e os Dantas; saque à casa dos Dantas; no Recife, a publicação das cartas amorosas; seu assassinato por João Dantas.

CAMARgo, Ayres de. Patriotas paulistas na Coluna Sul. São Paulo, Liberdade, 1925. 218 p. fot.

Relata a ação dos batalhões patrióticos contra os revolucionários de 1924. Desde 7 de julho organizaram-se em Itapetininga e Piraju batalhões civis, sob ordens dos Coronéis Ataliba Leonel e Fernando Prestes. Até setembro dêsse ano, êles perseguem as fôrças revolucionárias, indo até as barrancas do rio Paraná.

Organização dos batalhões; composição social de sua oficialidade; prestígio militar do coronelismo; número de bataIhões patrióticos; sua ação nos combates de Mayrink e Botucatu; coronelismo e hierarquia; coronelismo e exército.

CARDOSO, José Gastão. A heróica resistência da Princesa. Recife, Escola Industrial Agamenon Magalhães, 1954, 89 p. il.

Elogio de José Pereira, que levanta a cidade de Princesa contra João Pessoa, em 1930.
Proclamação de José Pereira contra João Pessoa. Biografia de José Pereira; sua amizade com Epitácio Pessoa e Suassuna; seu combate ao cangaceirismo; coronelismo; predomínio dos Pereiras desde o Império; coronelismo e finanças municipais.

CARVALHO, M. Balbino de (pseudônimo: Carvalhinho). A luta no Garças. Rio de Janeiro, Jacinto Ribeiro dos Santos, 1926. 59 p. il.

Relato da luta coronelística no Garças, zona diamantífera de Mato Grosso. E a história da rebelião do agrônomo José Morbeck contra o govêrno de Pedro Celestino e de seu ataque a vila de Santa Rita de Araguaia; depois, com o contraataque, chega-se a um acôrdo, permanencendo Morbeck no cargo intendente.

Trabalho escravo nas usinas de açúcar de Mato Grosso. Os coronéis impedem que 0 govêrno cobre impostos. Ataque de Morbeck a Santa Rita de Araguaia (1924). O desenrolar da luta (1925). 0 acôrdo entre o govêrno do estado e Morbeck.

CHAGAS, Américo. 0 chefe Horácio de Matos. São Paulo, s/e. 1961. 254 p. il.

Livro fundamental para o estudo do fenômeno do coronelismo na Bahia durante a primeira República. Além do caso de Horácio de Matos, o autor cita outros.

Sua infância. Nomes de outros coronéis. Ataque do coronel Militão a Brotas (comêço do século). Horácio ataca Campestre (1915), Brotas (1916) e Barra do Mendes (1919). Coronelismo e neutralidade; fuzilamento; guerra; auxílio das fôrças públicas. Luta eleitoral. Horácio a favor de Paulo Fontes (1919). Luta armada contra Antônio Moniz e J. J. Seabra. Intervenção federal (1920) e o Acôrdo. Seabra o nomeia Delegado Regional para $12 \mathrm{mu}$ - 
nicípios. O coronel deputado Manoel Alcântara. Horácio de Matos desarma a polícia em Lençóis. Cêrco de Lençóis pela polícia (1925) e a luta de Horácio contra o Governador Góes Calmon. Resumo completo da caminhada da Coluna Prestes pelo Brasil. Coluna Prestes quer estabelecer govêrno revolucionário no Maranhão (1925). Tática do $\mathrm{Ge}$ neral Mariante para acabar com a Coluna (Bahia, 1926). General Mariante contrata coronéis para atacar a Coluna. Ataques dos patriotas contra a Coluna. Horácio forma o bataIhão patriótico Lavras Diamantinas. Revolução de 1930 e o desarmamento dos coronéis baianos. Seu declínio.

Prisão dos maiores coronéis em 1931.

CORREA Filho, Virgílio. Pedro Celestino. Rio de Janeiro, Hélio Valverde, 1945,263 p. il.

História do amigo e partidário de Generoso Ponce. Da família latifundiária Corrêa da Costa, Celestino é um dos elementos que participam de tôda a história matogrossense na primeira República.

Revolução de 1906. Questão econômico-política do predomínio da Mate Laranjeira. História política do govêrno do General Caetano Manoel de Faria e Albuquerque e a Revolução de 1916. Relatórios do Governador Pedro Celestino sôbre as revoltas de 1922 e 1924.

DINIZ, Sílvio Gabriel. 0 gonçalvismo em Pitingui. Belo Horizonte, Editôra da RBEP, 1969. $130 \mathrm{p}$.

Estudo da luta pelo predomínio político de um município de Minas Gerais. Mostra a luta coronelística feita através de meios legais, como o domínio da prefeitura e dos cargos legislativos locais.

Coronelismo e domínio familiar. Chefes coronelísticos da região. Formas de oposição. Dinheiro público e coronelismo. Mudança de poder coronelístico na cidade. Sistema eleitoral: mesa, urna, cópias das atas; número de atas eleitorais; composição das mesas eleitorais entre 1904 e 1917; modelos de protesto contra as fraudes eleitorais; exemplo da plataforma eleitoral (1890); quadras populares e política.

GOYCOCHEA, Castilhos. Gumercindo Saraiva na Guerra dos Maragatos. Rio de Janeiro, Alba, 1943. 199 p. il., map.

Biografia do famoso caudilho gaúcho, chefe do $1 .^{\circ}$ Corpo do Exército Libertador Riograndense, o maior militar da Revolução de 1893.

O livro sofre de um sociologismo ultrapassado, com explicações superficiais de raça e ambientes geográficos. Mas tenta honestamente definir o tipo do gaúcho e o fenômeno guerreiro gaúcho.

Dados sôbre Gumercindo; sua origem social e política; história de suas campanhas; sua fuga dos conchavos políticos; sua modéstia e aproximação com seus soldados; sua volta do $\mathrm{Pa}$ raná ao Rio Grande do Sul; morte e paralelo com Pinheiro Machado.

GOYCOCHEA, Castilhos. 0 gaúcho na vida política brasileira. Pôrto Alegre, Globo, 1935. 209 p. Caracterização da mentalidade gaúcha, que oscila entre o espírito de fronteira (Gaspar Martins, Assis Brasil, etc.) e o da cidade (Castilho, Borges de Medeiros). E a desordem contra a ordem; Getúlio Vargas é o espírito plástico e maleável, que não está dentro dêste esquema. A partir desta dualidade, o autor relata a história republicana riograndense.

HORTA, Cid Rebelo. Famílias governamentais de Minas Gerais (in Segundo Seminário de Estudos Mineiros). Belo Horizonte, Universidade de Minas Gerais, 1956. 243 p.
Fundamental estudo sôbre o domínio oligárquico de determinadas famílias sôbre a vida econômica e política do estado. 0 autor mostra como a decadência de mineração leva elementos da camada rica urbana para a atividade agrícola. Com a Independência, os grupos rurais dominam a vida política e se elegem nos cargos executivos. O federalismo republicano possibilita um predomínio mais absoluto. 0 artigo traz a lista de tôdas as famílias dominantes, suas ligações e domínio.

IBGE. Brasil. Pantanais matogrossenses: devassamento e ocupação. Rio de Janeiro, IBGE, 1946. 170 p. il., mapas.

Estudo histórico e geográfico. Poder dos coronéis (representam a lei nos seus domínios); situação dos seus agregados.

LEAL, Victor Nunes. Coronelismo, enxada e voto: o município e o Regime representativo no Brasil. Rio de Janeiro, s/e 1948. $311 \mathrm{p}$.

Estudo do problema do coronelismo e sua base municipal. Origem da palavra coronelismo. Causa primária do fenômeno. A liderança no sistema $e$ dependência. A pequena propriedade no Brasil Sul (1940). Predomínio do latifúndio em São Paulo em 1934. Coronelismo: favores, domínio municipal, reciprocidade de favores (com o estado), causas, oposição e predomínio municipal. Moralidade administrativa municipal e estadual. Centralização

municipal no Império e descentralização na República. Rendas municipais e a Constituição de 1891. Coronelismo: polícia e organização judiciária. As leis eleitorais do Império e República e seu alcance. Federalismo e centralismo no sistema eleitoral da República.

LINS, Wilson. 0 Médio Sã

Francisco: uma sociedade de pastores e guerreiros. 2. ed. Salvador, Progresso, 1960. 228 p. 
Estudo histórico-sociológico do médio São Francisco. Trata do problema da fixação do homem no vale e a formação e desenvolvimento do coronelismo. Mostra que os coronéis são de origem agrária (fins do século XVIII até fins do século $X(X)$; depois, com 0 advento de novas correntes imigratórias, surgem nas cidades uma nova corrente de coronelismo (de origem comercial-agrícola). E esta corrente que funciona em grande parte da República.

Origem do coronelismo na região. História do coronel Militão Plácido de França Antunes. Outros coronéis da zona. A corrente imigratória, 0 comércio de maniçoba e a formação de nova corrente de coronéis. Coronel Franklin de Lins de Albuquerque e sua história. Coronelismo como fôrça armada. 0 caso do coronelismo em Urubu (Bahia). Coronel Franklin e a Revolução de 1930 . Coronelismo e as novas formas de produção capitalista.

LISBOA, Senador Coelho. Oligarquia, sêcas do Norte e clericalismo. Rio de Janeiro, Nacional, 1909. 245 p.

Discursos pronunciados no Senado em 1908. Ataques às oligarquias de Venâncio Neiva e Álvaro Machado, da Paraíba; a Afonso Pena; às negociatas da indústria da sêca no Norte; e ao incidente do Cardeal Arcoverde no Rio de Janeiro.

O autor ataca a oligarquia Neiva a partir de 1890; como êste sobe ao govêrno da Paraíba (1889). Aristides Lôbo e o desencanto com a República. Queda de Neiva (depois de 23/11/1891). A revolução contra a Junta Governativa e a subida de Alvaro Machado. Corrupção de Venâncio Neiva; como êste manda fechar jornais da oposição; empreguismo sob seu govêrno. Sêcas e corrupção. Incidente do Cardeal Arcoverde. Escolha de Davi Campista por Afonso Pena.
MAGALHAES, Tenente-Coronel Benevenuto. Guia prático para o oficial da Guarda Naçional. Rio de Janeiro, Oficial, 1898. 219 p.

Guia organizado por determinação do Dr. Amaro Cavalcanti, Ministro da Justiça e Negócios Interiores. Traz material completo sôbre o problema.

Transcrição de tôdas as leis, decretos e regulamentos, de 19 de setembro de 1850 a 14 de dezembro de 1896: organização, promoções e nomeações, patentes; têrmo de promessa, honras, fins, subordinação ao Ministério da Justiça e Negócios Interiores, limites de ação, deveres e atribuições dos oficiais, guerra, uniforme; todos os problemas correlatos entre oligarquia agrária e Guarda Nacional.

MELO, M. Rodrigues de. Patriarcas e carreiros. Rio de Janeiro, Pongetti, 1954. 273 p.

A primeira parte é estudo da vida e ação do coronel José Bezerra de Araújo Galvão (Rio Grande do Norte, Currais Novos).

Apesar de elogioso e ingênuo, apresenta exemplos para o estudo do fenômeno do coronelismo.

Vida agrária da oligarquia da terra. O coronel como juiz; sua ação e domínio em Currais Novos; fôrça política; luta armada; votos; política; sua fortuna; obrigações e serviços recebidos. Vida familiar da época.

MORAES, Walfrido. Jagunços e heróis: a civilização do diamante nas lavras da Bahia. Rio de Janeiro, Civilização Brasileira, 1963. 212 p. il.

Estuda o fenômeno Horácio de Matos e seu ambiente. Ascensão de Clementino de Matos, tio de Horácio. Paz com o coronel Militão (1909). Luta contra o coronel Manuel Fabrício de Oliveira e o cêrco de Campestre (1915). Luta com
Militão e tomada de Barra do Mendes (1916). Sucessão de A. Móniz e a Revolta do Sertão (1920). Coronéis que lutam a favor da Oposição (1920). A. Moniz e o General Cardoso de Aguiar pedem intervenção federal (fevereiro de 1920). Ernesto Simões Filho é quem teve idéia de pedir 0 apoio de Horácio para a Oposição. Acôrdo de março de 1920. Luta contra Senador Francisco Sá e o cêrco de Lençóis (1925). Convite para participar da Coluna Prestes. Ação contra a Coluna Prestes. Emissão de papel-moeda por Horácio (1927) e sua morte.

PINHEIRO, Irineu. 0 Joàzeiro do Padre Cícero e a Revolução de 1914. Rio de Janeiro, Irmãos Pongetti, 1938. 243 p.

Livro excelente, traz farta documentação sôbre as ligações de Floro Bartolomeu com o Padre Cícero. Fenômeno do coronelismo. $O$ ataque das fôrças legais contra Joàzeiro. Vitória dos jagunços (tomada de Crato) sôbre as fôrças do Coronel Franco Rabelo.

A documentação primária (cartas de Pinheiro Machado, Floro Bartolomeu, Padre Cícero, etc.) é valiosa.

O livro narra a rebelião, do seu início (9-12-1913) até a tomada de Crato (23-1-1914).

QUEIROZ, Maria Isaura Pereira de et alii. Estudos de sociologia e história. São Paulo, Anhembi, 1957. 303 p.

O ensaio da autora é o mandonismo local na vida política brasileira: estudo do problema do coronelismo; das chefias locais contra as tendências centralizadoras, da Colônia à Primeira República.

O problema na Colônia e Império; os podêres municipais e suas restrições progressivas na República.

QUEIROZ, Maria Isaura Pereira de. La "Guerre Sainte" au Brésil: le mouvement messianique 
du "Contestado". São Paulo, Universidade de São Paulo, Faculdade de Filosofia, Ciências e Letras, 1957. 299 p. il.

Tese apresentada à Escola Prática de Altos Estudos, Paris; uma análise sociológica do fenômeno messiânico, antecedida por considerações sôbre os fatôres históricos e sociológicos regionais.

O segundo João Maria e o início do ajuntamento de crentes (1912). Sua ideologia. Coronelismo em Santa Catarina. Primeiras lutas dos fanáticos (Palmas, Paraná, 1912) e a morte de João Maria. Nôvo agrupamento dos fanáticos no Contestado. Primeiras lutas e suas causas (1913). As diversas fases de lutas (fevereiro de 1914 até início de 1915). Fatôres que levam ao fracasso dos jagunços. Problemas da posse da terra. Nomes de coronéis situacionistas e da oposição no Contestado.
ROMERO, Sílvio. A geografia da politicagem: o Norte e o Sul do Brasil. s/e., 1912. 14 p.

Ataque a Pinheiro Machado e as oligarquias. Crítica a certos políticos que não querem dizer-se do Norte (decadente) e falam que seus estados pertencem ao Sul do País.

SOUZA, Antônio Fernandes. Antonio Paes de Barros e a política de Mato Grosso. São Paulo, Cinelândia, 1958. 101 p. il.

Defesa de usineiro, político e governador (1902-1906) de Mato Grosso contra as acusações contidas no livro de Generoso Ponce Filho.

Totó Paes, que abrira a usina mais moderna do estado, era o grande senhor que dominava extensa zona eleitoral. Na luta contra o predomínio de Generoso Ponce, êle é convocado pelos Murtinhos, tornando-se o elemento de maior fôrça dentro desta hoste. Com a Revolução de 1899 e a queda de Ponce, Totó Paes consegue chegar ao ápice do poder. Daí, para ser governador, foi um passo. Porém, o seu govêrno despótico e preponderante 0 afasta dos Murtinhos, que se vêem relegados. $A$ união dêstes com o vencido $e$ inimigo Ponce leva à Revolução de 1906 e à morte violenta de Totó Paes.

VIEIRA, Osvaldo Hermes e Silva. História da Polícia Civil de São Paulo. São Paulo, Cia. Editôra Nacional, 1955. 421 p.

Pesquisa sôbre a história, transformações e atribuições da polícia de São Paulo-Colônia aos dias de hoje. Mostra a mudança limitativa da ação da polícia devido à Constituição de 1891 e seus parágrafos relativos aos direitos do indivíduo. A reforma de 1905 e a luta contra o poder dos coronéis em São Paulo.

\section{Óltimes lançamentos da fundaĢo getólio vargas}

Planejamento Goveruamental

(A Experiência Brasileira)

Jorge Gustavo da Costa

O Estudo da Administraçāo Páblica

Dwight Waldo

Os Mercados de Capitais ua América Latina

Antonín Basch e Milic Kybal

Manual de Administraçãa da Produção, I e II

C. Machline, Kurt Weil, I. de Sá Motta

e Wolfgang Schoeps

Teoria Microeconômica

Mário Henrique Simonsen

Movimentos Partidários no Brasil

Paulo Roberto Motta

O Negro no Pará

Vicente Salles
Notas e Estudos de Português

Martinz de Aguiar

O Lazer no Planejamento Urbano

Ethel Bauzer Medeiros

Orçamento Páblico

Jesse Burkhead

Direito do Trabalho

Délio Maranhão

2. ${ }^{\mathrm{a}}$ edição

Contabilidade Industrial

Salvador Chevitarese

3. ${ }^{a}$ ediç̧ão

Usos e Abusos de Relações Páblicas

José Xavier de Oliveira

Sociologia nos Países Subdesenvolvidos

Uma Coletânea

Nas principais livrarias ou pelo reembòlso postal. Pedidos para a Editôra da Fundação Getúlio Vargas, Praia de Botafogo 188, CP 21.120, Rio de Janeiro, GB. 